\title{
Evaluation of Erianthus procerus Introgressed Sugarcane Clones for Water Deficit Stress and Red Rot Resistance
}

\author{
K. Mohanraj*, P.J. Oshin and A. Suganya \\ Division of Crop Improvement, ICAR-Sugarcane Breeding Institute, Coimbatore, India \\ *Corresponding author
}

\section{A B S T R A C T}

\section{Keywords}

Sugarcane, Water deficit stress, Red rot, Erianthus procerus, Intergeneric hybrid

Article Info

Accepted:

04 August 2019

Available Online:

10 September 2019
Sugarcane is one of the major commercial crops in India and its productivity is severely hampered by drought and red rot. It is essential to enhance the abiotic and biotic stress tolerance by exploiting novel and diverse source of germplasm for sugarcane improvement and sustain productivity. Of late considerable attention has been given to utilize Erianthus spp a wild relative of sugarcane. In this study, Erianthus procerus introgressed intergeneric hybrid and backcross hybrids were evaluated for water deficit stress and red rot resistance. The somatic chromosome number of backcross hybrids ranged from $2 \mathrm{n}=88$ to 94 and all the backcross hybrids were results of $n+n$ transmission. The intergeneric hybrid GU 04 (28) EO-2 and the back cross hybrids viz., GU 12-21, GU 12-23, GU 12-29 and GU 12-31 were resistant against the highly virulent mixed inoculum of $\mathrm{cf} 671$ and $\mathrm{cf}$ 94012 (Colletotricum falcatum). Three clones viz., GU 04 (28) EO-2, GU 12-28 and GU 12-34 recorded significantly higher shoot fresh weight, root fresh weight and root dry weight under water deficit stress condition and dry root weight showed positive and significant association (0.643) with stress tolerance index (STI). These E. procerus introgressed clones could serve as a potential donor for developing and enhancing drought and red rot resistance in sugarcane.

\section{Introduction}

Sugarcane (Saccharum spp) is a tall perennial plant belonging to the genus Saccharum and is an important commercial crop grown in both tropical and sub- tropical regions of the world. In India, sugarcane industry is the second largest agro- based industry next to textile industry and is cultivated in $4.73 \mathrm{mha}$ with the production of $376.9 \mathrm{mtonnes}$ and productivity of 79.65tonnes/ha in 2017-18 (ISMA). Among the different species in the genus Saccharum,
S. spontaneum $(2 \mathrm{n}=40$ to 128$)$ has been known for its high vigor, profuse tillering and strong ratooning ability as well as resistance to biotic and abiotic stresses. Modern sugarcane cultivars under cultivation are complex polyploidy aneuploids derived from the interspecific hybridization between Saccharum officinarum and the wild species Saccharum spontaneum $\mathrm{L}$. The slow rate of sugarcane breeding progress and narrow genetic base of modern cultivars was brought out by several sugarcane researchers 
(Arceneaux, 1965; Daniels, 1965) and attempts were made to cross sugarcane with other related genera of the "Saccharum complex" (Harlan and De Wet, 1971) to broaden and diversify the genetic base of sugarcane varieties.

Of late significant attention has been given to use Erianthus which is a wild relative of Saccharum to introgress valuable traits. Out of seven species in Erianthus, two species viz., E. arundinaceus and E. procerus have been valued in sugarcane improvement due to their desirable traits, such as their high biomass, vigour, ratooning ability, tolerance to biotic and abiotic stresses especially drought. The crossing between Saccharum and Erianthus is very difficult and one of major bottlenecks in intergeneric crosses is sterility in F1 hybrids which hinders further improvement. Successful production of intergeneric hybrids between Saccharum and Erianthus have been reported (D'hont et al., 1995; Ram et al., 2001; Cai et al., 2005, Fukuhara et al., 2013; Mohanraj and Nair, 2014). E. procerus $(2 \mathrm{n}=40)$ resembles E.arundinaceus $(2 \mathrm{n}=30,40$ and 60$)$ and $E$. kanashiroi Ohwi $(2 \mathrm{n}=60)$ but lacks vegetative cane and has large droopy silky panicles (Amalraj and Balasundaram, 2006). Attempts were made at ICAR-Sugarcane breeding Institute, Coimbatore to introgress desirable traits of Erianthus in sugarcane and diversify the genetic base and a novel intergeneric hybrid has been developed between Erianthus procerus and Saccharum officinarum and reported (Nair et al., 2017).

Predictions of climate change have indicated an increased variability of rainfall in the next 40 years and an increased risk of high temperature and drought. The effect of drought due to climate change on cane yield depends on plant's drought response and its occurrence with other abiotic and biotic stress factors (Zhao and Li, 2015). In sugarcane, drought and red rot are the most devastating stresses which can cause substantial yield losses. Exploitation of new and diverse sources of variation is needed to enhance the biotic and abiotic stress resistance and wild relatives would provide an important source of genetic diversity. Keeping the above facts in mind, the present study was initiated to assess the effect of water deficit stress on early growth of Erianthus procerus introgressed clones and their level of red rot resistance.

\section{Materials and Methods}

The experiment was conducted at ICARSugarcane Breeding Institute, Coimbatore, India. The experiment site is situated at an altitude of $427 \mathrm{MSL}$ at $11^{\circ} \mathrm{N}$ latitude and $77^{\circ} \mathrm{E}$ longitude. The experimental material consisted of F1 intergeneric hybrid and $\mathrm{BC} 1$ progenies of Erianthus procerus $\mathrm{x}$ S.officinarum and two commercial cultivars Co 06027 and Co 775. The list of clones used in this study is given in the table 1 .

\section{Cytological studies}

To confirm the hybridity of intergeneric and backcross hybrids, cytological studies were carried out to determine the somatic chromosome numbers. Single budded setts of F1 intergeneric hybrid, BC1 hybrids and their parents were plated in pots with sand and root tips were collected for mitotic analysis. The root tips were pre-treated with saturated solution of $\alpha$-bromonaphthalene at $4^{\circ} \mathrm{C}$ for 2 $\mathrm{h}$.

After washing the roots were fixed in alcohol: acetic acid (3:1) solution and kept at $4{ }^{\circ} \mathrm{C}$ overnight. The washed root tips were hydrolysed and stained and slides were prepared through the squash method in $1 \%$ acetocarmine. In each clone at least 10 wellspread metaphase plates were counted for determining the chromosome number. 
Screening for red rot resistance under controlled condition testing

The clones were screened for red resistance against the highly virulent mixed inoculum of cf 671 and cf 94012 (Colletotricum falcatum) under controlled condition testing (CCT) and the disease reaction was scored as per Mohanraj et al., (1997).

\section{Screening for water deficit stress}

A pot experiment was undertaken in a glasshouse conditions during March 2016. The stalk of 10 clones was cut in to pieces of single active buds and pre germinated. The soil mixture was filled in the plastic containers of $27.5 \mathrm{~cm}$ diameter and $35 \mathrm{~cm}$ height with a total soil capacity of $22 \mathrm{kgs}$ with uniform bulk density. The uniformly-germinated single buds were then planted in the individual pots. A factorial randomized block design with two water regimes (well-watered and water deficit stress) as factor A and 10 clones as factor B was carried out with five replications. Water was supplied daily to the experiment at normal from planting to 60 days after planting (DAP). After 60 DAP, water level at field capacity was maintained throughout the experiment for well-watered control.

For water deficit treatment, water was withheld at 60 to 75 DAP. The moisture content of the soil in the pots was measured gravimetrically before and after stress period. The data on shoot fresh weight (g/plant), maximum root length $(\mathrm{cm})$, root fresh weight (g/plant), shoot dry weight (g/plant) and root dry weight ( $\mathrm{g} / \mathrm{plant}$ ) was measured after stress period. In addition, Stress Tolerance Index (STI) was calculated by using the following formula (Maiti et al., 1994).

STI =Dry weight of plant in stress (g) / Dry weight of plant in control (g).

\section{Statistical analysis}

Analysis of variance was performed for shoot fresh weight, maximum root length, root fresh weight, root dry weight and shoot dry weight according to a factorial design, where main effects were significant, least significance difference (LSD) was used to compare means. Simple correlations were computed to find out the interrelationship among the drought tolerance and growth traits.

\section{Results and Discussion}

\section{Cytological studies and confirmation of hybridity}

The back cross hybrids of E.procerus and their parents were analysed cytologically and chromosome numbers were determined (Table 1 and Fig. 1). The somatic chromosome number of intergeneric hybrid GU 04(28)EO2 has been confirmed and reported as $2 n=80$ (Nair et al., 2017).The somatic chromosome number of the seven $\mathrm{BC} 1$ hybrids ranged from 88 to 94 and the parent Co 06027 had $2 \mathrm{n}=108$. The BC hybrids GU 12-28 and GU 12-31 recorded the somatic chromosome number of $2 n=88$ and maximum of $2 n=94$ was recorded in GU 12-23.

\section{Red rot resistance}

The red rot rating of the $\mathrm{F} 1$ hybrid, $\mathrm{BC}$ hybrids and their parents against the mixed inoculum of cf 671 and cf 94012 (Colletotricum falcatum) is given in the table 1. The intergeneric hybrid has shown resistant reaction and the back cross hybrids viz., GU 12-21, GU 12-23, GU 12-29 and GU 12-31 were also resistant and other BC hybrids were moderately resistant.

Performance of $E$. procerus introgressed clones under water deficit condition

The mean performance of the intergeneric and $\mathrm{BC}$ hybrids involving E. procerus for early 
growth traits under normal and water deficit condition is given in the table 2. Analysis of variance for early growth traits in intergeneric and backcross hybrids of E.procerus showed that there was a highly significant difference among the treatments (well watered and water deficit stress) as well as genotypes for shoot fresh weight, root fresh weight, shoot dry weight and root dry weight. For maximum root length, though the genotypes showed significant differences, the treatments were not significant. The interaction effect of treatment $x$ genotype in non-significant in only two traits viz., shoot fresh weight and maximum root length.

Three clones viz., GU 04 (28) EO-2, GU 1228 and GU 12-34 recorded significantly higher shoot fresh weight, root fresh weight and root dry weight under water deficit stress condition. The clones GU 12-28 and GU 04
(280EO-2 also recorded significantly higher shoot dry weight under stress. The clone GU 12-28 also recorded the highest shoot weight under water deficit condition followed by GU 04(28)EO-2 (94.00g/plant). Though the treatment means were non-significant for root length, there was significant difference among genotypes. Under stress, the

\section{Stress tolerance index (STI)}

The percent reduction in shoot dry biomass and stress tolerance index for 10 clones in given in the table 3. The BC hybrid GU 12-23 recorded the highest stress tolerance index of 0.81 followed by the hybrid GU 12-31 (0.80) andGU 12-28 (0.78). The total dry biomass reduction under water deficit stress condition ranged from $19.08 \%$ in GU $12-23$ to $60.24 \%$ in Co 775 .

Table.1 Parentage, somatic chromosome number and red rot resistance of the clones used

\begin{tabular}{|l|l|l|l|l|l|c|}
\hline $\begin{array}{l}\text { Sl. } \\
\text { No }\end{array}$ & Clone & $\begin{array}{l}\text { Gener } \\
\text { ation }\end{array}$ & Female & Male & $\begin{array}{l}\text { Somatic } \\
\text { chromosome } \\
\text { no. (2n) }\end{array}$ & $\begin{array}{l}\text { Red rot } \\
\text { resistance }\end{array}$ \\
\hline $\mathbf{1}$ & GU 04(28) EO-2 & F1 & IND 90-776 & PIO 96-435 & 80 & R \\
\hline $\mathbf{2}$ & GU 12- 20 & BC1 & GU 04(28) EO-2 & Co 06027 & 90 & MR \\
\hline $\mathbf{3}$ & GU 12- 21 & BC1 & GU 04(28) EO-2 & Co 06027 & 90 & R \\
\hline $\mathbf{4}$ & GU 12- 23 & BC1 & GU 04(28) EO-2 & Co 06027 & 94 & R \\
\hline $\mathbf{5}$ & GU 12- 28 & BC1 & GU 04(28) EO-2 & Co 06027 & 88 & MR \\
\hline $\mathbf{6}$ & GU 12- 29 & BC1 & GU 04(28) EO-2 & Co 06027 & 92 & R \\
\hline $\mathbf{7}$ & GU 12- 31 & BC1 & GU 04(28) EO-2 & Co 06027 & 88 & R \\
\hline $\mathbf{8}$ & GU 12-34 & BC1 & GU 04(28) EO-2 & Co 06027 & 90 & MR \\
\hline $\mathbf{9}$ & Co 06027 & - & CoC 671 & IG 91-1100 & 108 & MR \\
\hline $\mathbf{1 0}$ & Co 775 & - & POJ 2878 & Co 371 & - & S \\
\hline
\end{tabular}

R: Resistant, MR: Moderately Resistant 
Table.2 Performance of intergeneric and backcross hybrids involving E.procerus under well watered (WW) and water deficit stress (WS)

\begin{tabular}{|c|c|c|c|c|c|c|c|c|c|c|c|c|c|c|c|c|}
\hline \multirow{2}{*}{$\begin{array}{l}\text { Sl. } \\
\text { No }\end{array}$} & \multirow[t]{2}{*}{ Clones } & \multicolumn{3}{|l|}{ SFW } & \multicolumn{3}{|l|}{ MRL } & \multicolumn{3}{|l|}{ RFW } & \multicolumn{3}{|l|}{ SDW } & \multicolumn{3}{|l|}{ RDW } \\
\hline & & WW & WS & Mean & WW & WS & Mean & WW & WS & Mean & WW & WS & Mean & WW & WS & Mean \\
\hline 1 & Co 775 & 158.50 & 63.00 & 110.75 & 93.00 & 73.00 & 83.00 & 38.50 & 20.00 & 29.25 & 73.81 & 28.35 & 73.81 & 8.05 & 4.20 & 6.12 \\
\hline 2 & GU04(28)EO-2 & 175.00 & 94.00 & 134.50 & 79.25 & 72.50 & 75.88 & 46.00 & 34.50 & 40.25 & 83.31 & 43.81 & 83.31 & 9.30 & 9.27 & 9.28 \\
\hline 3 & GU 12-20 & 80.00 & 31.00 & 55.50 & 111.00 & 97.00 & 104.00 & 41.00 & 18.00 & 29.50 & 28.80 & 14.81 & 28.80 & 8.80 & 5.75 & 7.27 \\
\hline 4 & GU 12-21 & 80.00 & 49.00 & 64.50 & 85.25 & 76.50 & 80.88 & 21.50 & 20.50 & 21.00 & 48.80 & 29.89 & 48.80 & 6.80 & 6.27 & 6.53 \\
\hline 5 & GU 12-23 & 59.00 & 53.00 & 56.00 & 73.00 & 81.50 & 77.25 & 41.50 & 18.00 & 29.75 & 24.31 & 21.73 & 24.31 & 9.30 & 5.30 & 7.30 \\
\hline 6 & GU 12-28 & 195.00 & 157.50 & 176.25 & 82.50 & 87.00 & 84.75 & 88.00 & 37.00 & 62.50 & 85.31 & 71.81 & 85.31 & 17.79 & 8.27 & 13.03 \\
\hline 7 & GU 12-29 & 111.50 & 74.00 & 92.75 & 65.25 & 73.50 & 69.38 & 49.50 & 25.50 & 37.50 & 52.81 & 35.31 & 52.81 & 9.80 & 6.70 & 8.25 \\
\hline 8 & GU 12-31 & 87.00 & 78.00 & 82.50 & 83.75 & 85.50 & 84.63 & 47.00 & 35.00 & 41.00 & 32.71 & 25.81 & 32.71 & 9.79 & 8.27 & 9.03 \\
\hline 9 & GU 12-34 & 100.00 & 89.00 & 94.50 & 84.00 & 59.75 & 71.88 & 68.00 & 34.50 & 51.25 & 41.80 & 31.00 & 41.80 & 13.30 & 8.70 & 11.00 \\
\hline \multirow[t]{4}{*}{10} & Co 06027 & 99.00 & 49.00 & 74.00 & 58.50 & 62.50 & 60.50 & 40.00 & 13.50 & 26.75 & 37.81 & 18.31 & 37.81 & 13.80 & 4.27 & 9.03 \\
\hline & Mean & 114.50 & 73.75 & & 81.55 & 76.88 & & 48.10 & 25.65 & & 50.94 & 32.08 & & 10.67 & 6.72 & \\
\hline & & A & B & $A \times B$ & A & B & $A \times B$ & A & B & $A \times B$ & A & B & $A \times B$ & A & B & $A \times B$ \\
\hline & $\mathrm{CD}(.05)$ & 14.64 & 32.75 & N/A & N/A & 17.48 & N/A & 5.04 & 11.28 & 15.96 & 9.03 & 20.20 & 28.57 & 1.14 & 2.55 & 3.60 \\
\hline
\end{tabular}

SFW; shoot fresh weight (g/plant); MRL: Maximum root length (cm); RFW: Root fresh weight (g/plant) SDW; shoot dry weight (g/plant); RDW: Root dry weight (g/plant)

Table.3 Percent reduction in total dry biomass and stress tolerance index in E.procerus introgressed clones

\begin{tabular}{|l|l|l|l|}
\hline SI.No & Clones & $\begin{array}{l}\text { \% } \\
\text { reduction }\end{array}$ & STI \\
\hline $\mathbf{1}$ & Co 775 & 60.24 & 0.40 \\
\hline $\mathbf{2}$ & GU04(28)EO-2 & 42.68 & 0.57 \\
\hline $\mathbf{3}$ & GU 12-20 & 45.32 & 0.55 \\
\hline $\mathbf{4}$ & GU 12-21 & 34.96 & 0.65 \\
\hline $\mathbf{5}$ & GU 12-23 & 19.08 & 0.81 \\
\hline $\mathbf{6}$ & GU 12-28 & 22.33 & 0.78 \\
\hline $\mathbf{7}$ & GU 12-29 & 32.90 & 0.67 \\
\hline $\mathbf{8}$ & GU 12-31 & 19.81 & 0.80 \\
\hline $\mathbf{9}$ & GU 12-34 & 27.95 & 0.72 \\
\hline $\mathbf{1 0}$ & Co 06027 & 56.25 & 0.44 \\
\hline
\end{tabular}


Table.4 Correlation coefficients between water deficit tolerance and early growth traits of intergeneric and backcross hybrids involving E.procerus

\begin{tabular}{|l|l|l|l|l|l|l|}
\hline & STI & SFW & MRL & RFW & SDW & RDW \\
\hline STI & 1.000 & & & & & \\
\hline SFW & 0.492 & 1.000 & & & & \\
\hline MRL & 0.190 & -0.004 & 1.000 & & & \\
\hline RFW & 0.571 & $0.813 * *$ & 0.017 & 1.000 & & \\
\hline SDW & 0.550 & $0.950^{* *}$ & 0.136 & 0.720 & 1.000 & \\
\hline RDW & $0.643 *$ & $0.659 *$ & 0.017 & $0.935^{* *}$ & 0.629 & 1.000 \\
\hline
\end{tabular}

SFW; shoot fresh weight (g/plant); MRL: Maximum root length (cm); RFW: Root fresh weight (g/plant) SDW; shoot dry weight (g/plant); RDW: Root dry weight (g/plant)

Fig.1 Somatic chromosome number of the intergeneric and backcross hybrids of Erianthus procerus
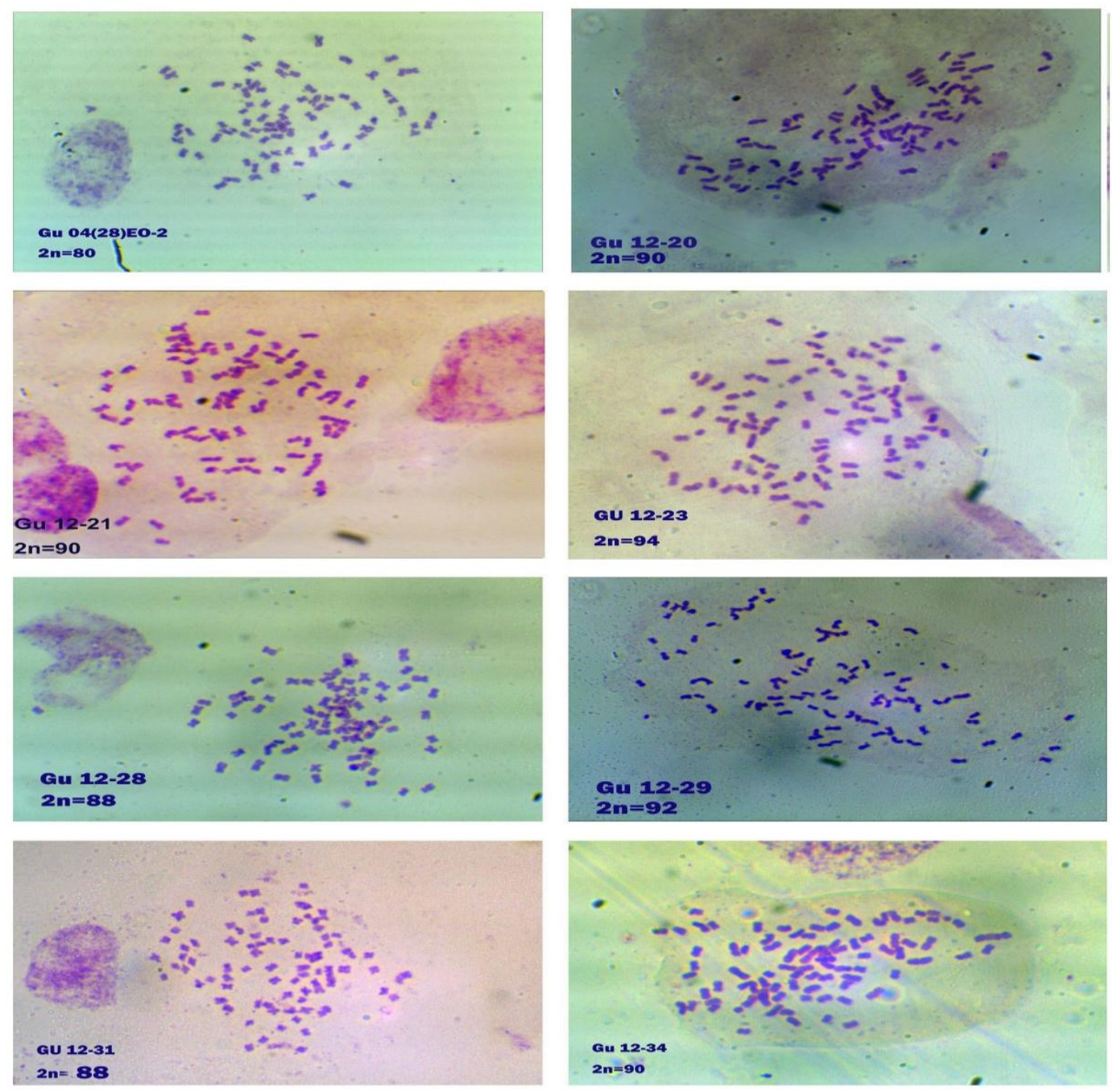


\section{Correlation between water deficit tolerance and early growth traits}

The correlation between early growth traits and drought tolerance index (DTI) is given in the table 4. The association between STI and root dry weight was positive and significant. The shoot fresh weight showed significant correlation with root fresh weight, shoot dry weight and root dry weight. There was also high significant correlation was observed between root fresh weight and root dry weight.

The results of cytological analysis showed that the somatic chromosome number of the intergeneric hybrid GU 04 (28) EO-2 was $2 \mathrm{n}=80$. In backcross hybrids, it ranged from $2 n=88$ to 94 which were the results of $n+n$ transmission and confirming its true hybridity. The F1 hybrid was resistant to red rot even against mixed inoculum of $\mathrm{cf} 671$ and cf 94012 (Colletotricum falcatum) and the $\mathrm{BC}$ hybrids were either resistant or moderately resistant showing the potential of Erianthus procerus introgressed clones as a novel source for red rot resistance.

Breeding for drought tolerance is largely dependent on the environment under which the plants are grown. Traditionally, important sources of sugarcane germplasm possessing drought tolerance have been found in the species S.spontaneum. Recently, the Erianthus were also reported as possessing drought tolerance (Fukuhara, et al 2013). These wild species represent important genetic variation that could be exploited in breeding for drought tolerance in sugarcane. Roots play an important role in overall drought tolerance. Some sugarcane genotypes avoid drought by rooting at greater depths and thus reaching and extracting soil moisture found in these regions of the soil profile. A study of root systems is vital to elucidate mechanisms that condition drought tolerance as drought can effect sugarcane growth and development anytime during the season. Studies have been conducted to identify root architecture differences in sugarcane (Saliendra and Meinzer, 1992; Smith et al., 2005; Jangpromma et al., 2012), but knowing which root traits are important to overall drought tolerance is critical when breeding for root systems that contribute to drought tolerance. One of the objectives of this study was to screen the $\mathrm{BC} 1$ hybrids of E.procerus under water deficit stress during early growth stage and assess the effect of drought on shoot and root traits.

In the present study, E.procerus introgressed clones were evaluated for their tolerance under water deficit condition. Stress tolerance index (STI) was calculated and clones with high STI were identified as drought tolerant ones. Water stress was given for a short period of 15 days and there was significant difference among well watered and water deficit stress for shoot fresh weight, shoot dry weight, root fresh weight and root dry weight. Jangpromma et al., (2012) has also observed significant reduction in root dry weight in set sugarcane varieties evaluated under water stress condition. Though there was no significant reduction or increase in root length underwater deficit stress condition, genotypes performed differently. Among the traits affected by water stress, maximum reduction of $46.69 \%$ was observed in root fresh weight which indicated that the root growth is hindered under drought. Saliendra and Meinzer, (1992) also reported reduced root growth in sugarcane when the soil water status reduced to a water potential of -0.07 MP. The reductions in root traits as affected by drought have been reported in other crops such as in rice (Wang et al., 2009), and sorghum (Tsuji et al., 2005).

Water stress has also significantly reduced shoot fresh weight which mainly determines 
the total biomass production. Significant differences were observed among the genotypes for shoot fresh weight, root length, root fresh weight, shoot dry weight and root dry weight. The back cross hybrid GU 12-28 was the best under water deficit stress condition for all these traits. The BC hybrid GU 12-20was poorest in terms of fresh shoot weight but had the highest root length among the genotypes. The reduced shoot weight in GU 12-20 may be due to the fact that it had few shoot roots which was reflected in the low root weight. Root weight contributes more to the drought tolerance. Most of the crops tend to produce more roots under water stress condition to forage water from deeper layers. The intergeneric hybrid GU 04(28) EO-2 had the highest growth rate of $1.08 \mathrm{~cm}$ per day under water stress condition. Desilva et al., (2008) found high variations among sugarcane genotypes for stalk number, stalk height, stalk diameter, stalk weight and cane yield. The interaction effects between genotypes and water regimes were significant for root fresh weight, shoot dry weight, root dry weight and these results showed differential responses under water stress.

The association studies between the early growth traits in Erianthus procerus introgressed clones with STI showed only dry root weight had positive and significant association (0.643). But Jangpromma et al., (2012) observed positive association stronger association between biomass and root traits (root length, root surface area, root volume and root dry weight) under recovery phase. Therefore, drought tolerance may be achieved by selection of larger root system and the Erianthus procerus introgressed clones are better sources for imparting and enhancing resistance to drought and red rot.

\section{Acknowledgement}

Authors are thankful to the Director, ICARSugarcane Breeding Institute, Coimbatore,
India for his support and providing necessary facilities to carry out this research work

\section{References}

Amalraj, V.A., and Balasundaram, N. 2006. On the taxonomy of the members of 'Saccharum complex'. Genet Resour Crop Evol 53: 35-41.

Arceneaux, G. 1965. Cultivated sugarcanes of the world and their botanical derivation. Proc. ISSCT, 12: 844-854.

Cai, Q., Aitken, K., Deng, H., Chen, X.W., Fu, C., Jackson, P.A., and McIntyre, C.L. 2005. Verification of the introgression of Erianthus arundinaceus germplasm into sugarcane using molecular markers. Pl. Breeding 124: 322-328.

Daniels, J. 1965. Improving sugarcane breeding methods to increase yields. Proc. ISSCT. 12:742-749.

De Silva, A., Silva, J.A.G., Enciso, J., Sharma, V., Jifon, J. 2008. Yield components as indicators of drought tolerance of sugarcane. Sci. Agric. (Piracicaba, Braz.), 65(6):620-627

D'hont, A., Rao, P., Feldmann, P., Grivet, L., Islam-Faridi, N., et al., (1995). Identification and characterization of sugarcane intergeneric hybrids, Saccharum officinarum $\times$ Erianthus arundinaceus, with molecular markers and DNA in situ hybridization. TheorAppl Genet 91: 320-326.

Fukuhara, S., Terajima, Y., Irei S., Sakaigaichi, T., Ujihara, K., (2013) Identification and characterization of intergeneric hybrid of commercial sugarcane (Saccharum spp. hybrid) and Erianthus arundinaceus (Retz.) Jeswiet. Euphytica 189: 321-327.

Harlan, J.R., and de Wet, J.M.J. 1971. Towards a rational classification of cultivated plants. Taxon. 20: 509-517.

ISMA, retrieved from 
https://www.indiansugar.com/Statics.as $\mathrm{px}$

Jangpromma, N., Thammasirirak, S., Jaisil, P., and Songsri, P. 2012. Effects of drought and recovery from drought stress on above ground and root growth, and water use efficiency in sugarcane (Saccharum officinarum L.) Aus J Crop Sci, 6(8):1298-1304

Maiti, R.K., De La Rosa, M.I. and Sandoval, N.D. 1994. Genotypic variability in glossy sorghum lines for resistance to drought, salinity and temperature stress at the seedling stage. J Pl Physiol, 143:241-244

Mohanraj, D., Padmanaban, P., Viswanathan, R., Alexander, K.C. 1997. Sugarcane screening for red rot resistance. Sugarcane 3: 18-23

Piperidis, N., Chen, J., Deng, H., Wang, L., Jackson, P. 2010. GISH characterization of Erianthus arundinaceus chromosomes in three generations of sugarcane intergeneric hybrids. Genome 53: $331-336$

Ram, B., Sreenivasan, T., Sahi, B., Singh, N. 2001. Introgression of low temperature tolerance and red rot resistance from Erianthus in sugarcane. Euphytica 122: 145-153.

Saliendra, N.Z., and Meinzer, F.C. 1992. Genotypic, developmental and droughtinduced differences in root hydraulic conductance of contrasting sugarcane cultivars. J Exp Bot 43: 1209-1217

Smith, D.M., Inman-Bamber, N.G., Thorburn, P.J. 2005. Growth and function of the sugarcane root system. Field Crop Res 92: 169-183

Zhao, D., and Li, Y. 2015. Climate Change and Sugarcane Production: Potential Impact and Mitigation Strategies. International Journal of Agronomy, Article ID 547386, http://dx.doi.org/10.1155/2015/547386

\section{How to cite this article:}

Mohanraj, K., P.J. Oshin and Suganya, A. 2019. Evaluation of Erianthus procerus Introgressed Sugarcane Clones for Water Deficit Stress and Red Rot Resistance. Int.J.Curr.Microbiol.App.Sci. 8(09): 590-598. doi: https://doi.org/10.20546/ijcmas.2019.809.071 